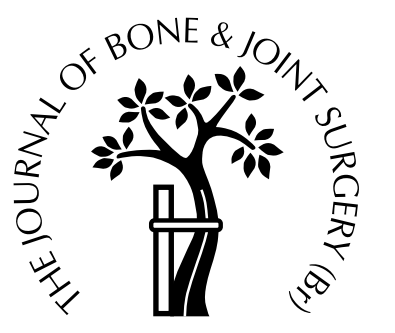

\title{
Fractures of the neck of the radius in children
} EARLY EXPERIENCE WITH INTRAMEDULLARY PINNING

\author{
Dorothea Stiefel, Martin Meuli, Stefan Altermatt \\ From the University Children's Hospital, Zürich, Switzerland
}

T he treatment of fractures of the neck of the radius in children is difficult, particularly if the angulation of the fracture exceeds $60^{\circ}$. Since 1994 we have used closed reduction and stabilisation with an intramedullary Kirschner wire in patients with grade-IV fractures according to the classification of Judet et al. In a retrospective analysis of a two-year period (1994 to 1996), 324 children with fractures of the elbow were treated in our department. Of these, $29(9 \%)$ had a fracture of the neck of the radius; six were grade-IV injuries (1.9\%). Five of the latter had an excellent postoperative result with normal movement of the elbow and forearm. One patient with a poor result had a concomitant dislocation of the elbow.

Our results suggest that closed reduction and intramedullary pinning of grade-IV fractures allows adequate stabilisation while healing occurs.

J Bone Joint Surg [Br] 2001;83-B:536-41.

Received 2 February 2000; Accepted after revision 4 July 2000

D. Stiefel, MD, Fellow in Paediatric Surgery

M. Meuli, MD, Consultant in Paediatric Surgery

S. Altermatt, MD, Consultant in Paediatric Surgery

Department of Surgery, University Children's Hospital, Steinwiesstrasse 75, 8032 Zürich, Switzerland.

Correspondence should be sent to Dr S. Altermatt.

(C)2001 British Editorial Society of Bone and Joint Surgery 0301-620X/01/411060\$2.00
Injuries to the elbow in children are common and fractures of the neck of the radius represent $5 \%$ to $10 \% .^{1-3}$ The anatomical complexity of the elbow and its blood supply makes treatment difficult. The head of the radius and its blood supply can be damaged by the injury itself and by surgical manipulation such as in open reduction. ${ }^{2-11}$ As a result, closed techniques using percutaneous Kirschner (K-) wires have been developed. ${ }^{12,13}$ Satisfactory reduction may not be achieved consistently, and because the K-wires are removed immediately after, dislocation can recur. ${ }^{7,14-16}$ Formal fixation of these fractures is preferable, and closed intramedullary pinning (CIMP), as proposed by GonzálezBuendia et $\mathrm{al}^{17}$ and Métaizeau et al, ${ }^{7}$ combines non-invasive closed reduction with internal fixation fulfilling both requirements.

We report our results obtained since November 1994 when we began to use CIMP instead of open reduction and transcondylar fixation.

\section{Patients and Methods}

We grade fractures of the neck of the radius according to the classification of Judet, Judet and Lefranc ${ }^{18}$ (Fig. 1). Grade-I and grade-II fractures are treated by a cast with no reduction, grade-III by closed reduction and a cast, and grade-IV by CIMP, if necessary using percutaneous $\mathrm{K}$ wires to aid reduction. Between November 1994 and October 1996, we treated 324 children with fractures at the elbow, $29(9 \%)$ of whom had fractures of the neck of the radius. Six $(1.9 \%)$ presented with a grade-IV fracture. The relevant information regarding the mechanism of injury, the angulation of the fracture, other injuries, and the time of surgery are given in Table I.

Under general anaesthesia, the entire upper limb is prepared, draped, and placed on a hand table. Under guidance of an image intensifier, a small incision is made about $1.5 \mathrm{~cm}$ above the epiphyseal plate on the radial side of the distal radial metaphysis. The soft tissue is dissected under direct vision taking care not to injure the cutaneous branch of the radial nerve, muscles or tendons. The cortex is exposed and perforated using a Pfriem-type trocar. A K-wire (1.6 to $2.0 \mathrm{~mm}$ in diameter, depending on age) with a slightly bent end is introduced into the intramedullary canal and gently pushed cranially until it reaches the inferior 


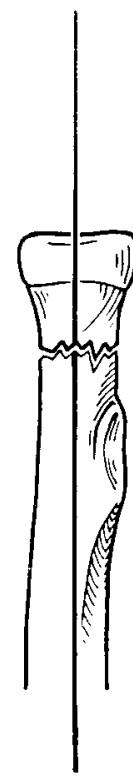

I

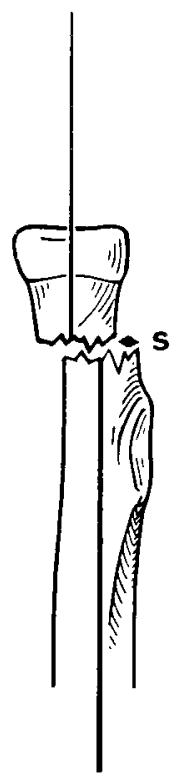

II

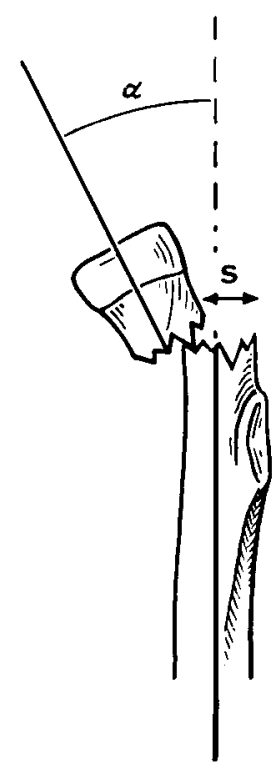

III

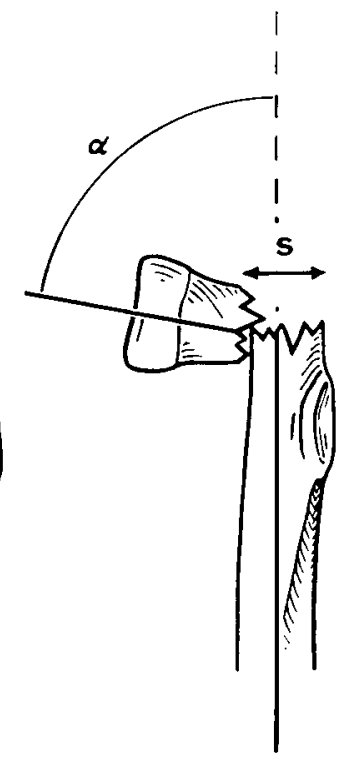

IV

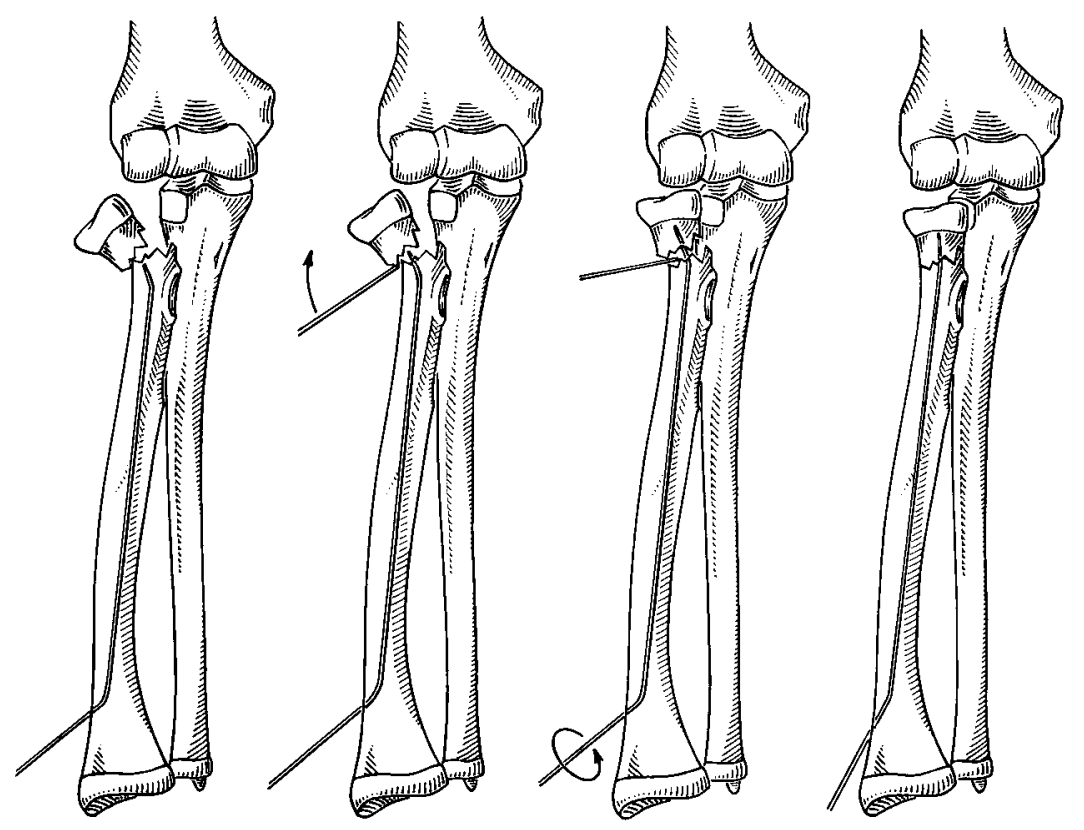

Fig. 2

Diagram showing reduction of the head of the radius by the leverage method and intramedullary pinning with a K-wire. Note the slightly bent tip, first pointing laterally. Once placed in the radial head it is rotated $180^{\circ}$ along its axis.

Table I. Mechanism of injury, angulation of the fracture, concomitant injuries, time of surgery, and outcome in the six patients with grade-IV fractures

\begin{tabular}{lllllll}
\hline $\begin{array}{l}\text { Age } \\
\text { (yr } \mathbf{m t h})\end{array}$ & Gender & $\begin{array}{l}\text { Mechanism } \\
\text { of injury }\end{array}$ & $\begin{array}{l}\text { Fracture } \\
\text { angulation } \\
\text { (degrees) }\end{array}$ & $\begin{array}{l}\text { Concomitant } \\
\text { injuries }\end{array}$ & $\begin{array}{l}\text { Time between } \\
\text { injury and surgery }\end{array}$ & Results \\
\hline 7 & M & Fall, 1 m & 60 & None & 4 days & Excellent \\
109 & F & Fall over a ball & 75 & Elbow dislocation & 2 days & Poor \\
96 & F & Fall, $0.6 \mathrm{~m}$ & 60 & None & 1 day & Excellent \\
67 & M & Tripping & 65 & None & 3 days & Excellent \\
98 & F & Fall, $0.4 \mathrm{~m}$ & 80 & None & Excellent \\
7 & F & Fall from a bar & $45, \mathrm{~S}>1 / 1$ & $\begin{array}{l}\text { Fracture of the shaft } \\
\text { of the ulna }\end{array}$ & 4 days & Excellent \\
\hline
\end{tabular}



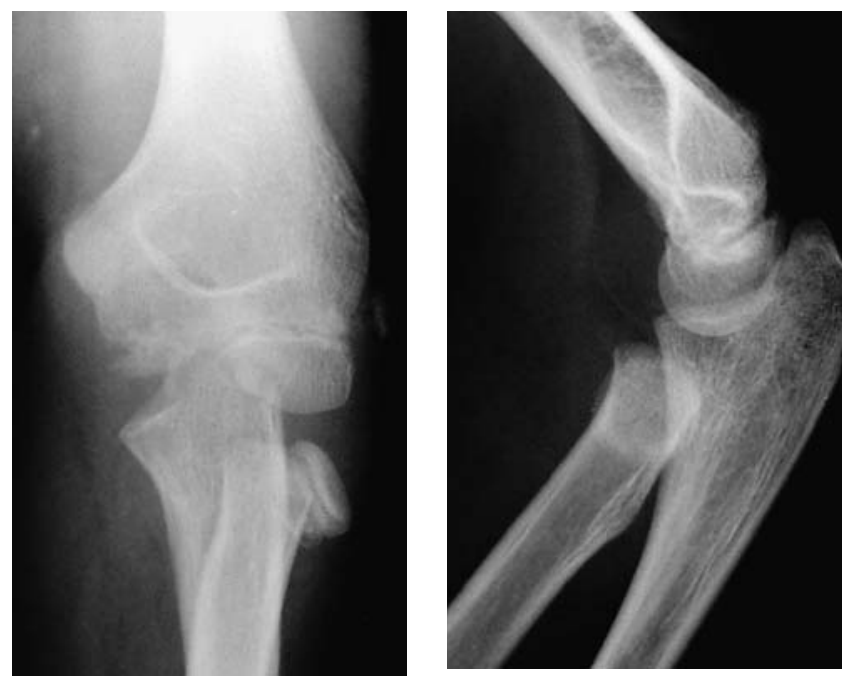

Fig. 3a
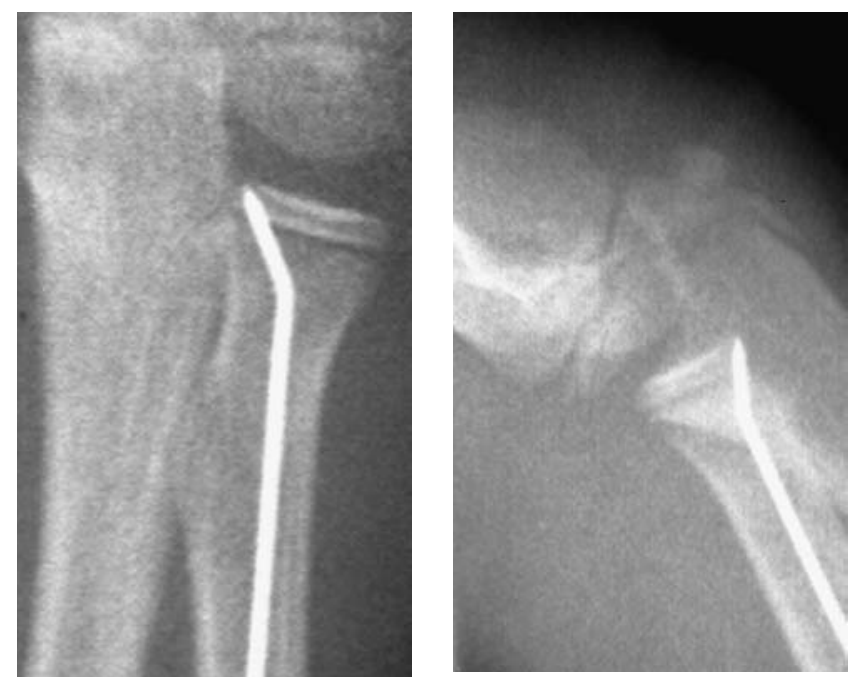

Fig. 3b
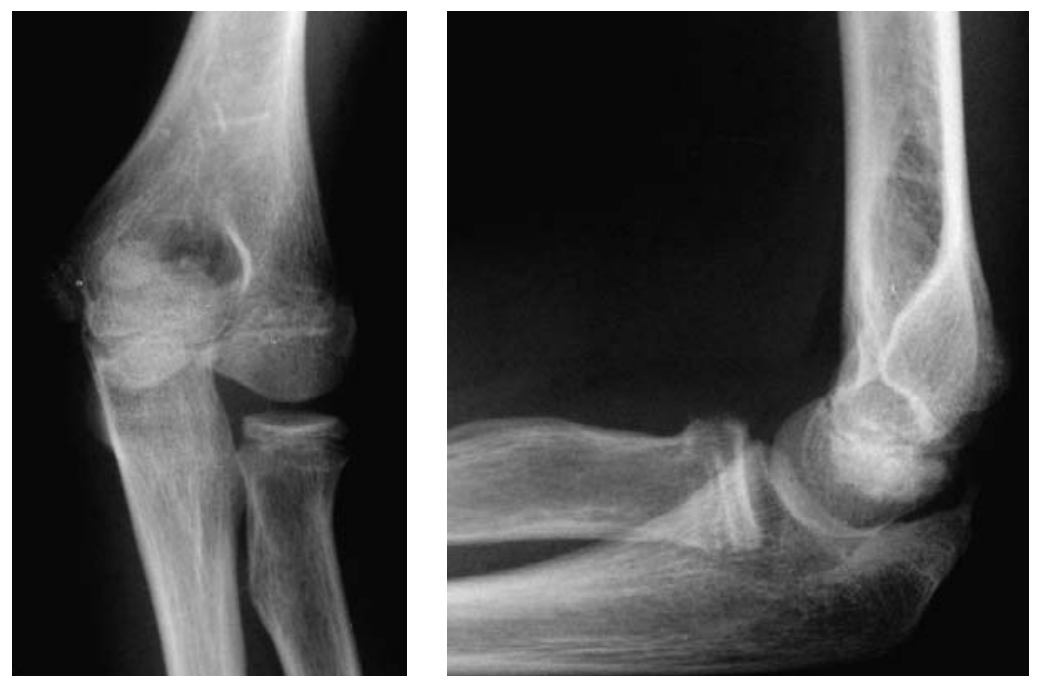

Radiographs showing anteroposterior (left) and lateral (right) views of the elbow of a 9.5-year-old girl. Figure $3 \mathrm{a}$ - Preoperative radiographs showing a grade-IV fracture with an angulation of $60^{\circ}$. Figure $3 \mathrm{~b}$ - Intraoperative radiographs after closed reduction and intramedullary pinning with a K-wire. Figure $3 \mathrm{c}$ - Follow-up radiographs showing an excellent outcome 12 months after the operation.

Fig. 3c

aspect of the displaced epiphysis. Then, with the elbow under a moderate varus stress, the fracture is reduced by external manipulation. If this manoeuvre fails, i.e., the intramedullary K-wire does not reach the fragment or does not achieve acceptable reduction of the angulation to $20^{\circ}$ to $30^{\circ}$ in younger and $10^{\circ}$ to $15^{\circ}$ in older children, further reduction is achieved by percutaneous leverage of the head with a K-wire as described by Akatsu ${ }^{12}$ and Feray ${ }^{13}$ (Fig. 2). The intramedullary $\mathrm{K}$-wire is then pushed into the head, with the tip still pointing radially. In order to reduce the remaining radial-lateral displacement, the wire is rotated through $180^{\circ}$ so that the tip points towards the ulna, thereby forcing the fragment to shift medially and facilitating anatomical reduction of the radial head within the joint (Fig. 3). Finally, the elbow is immobilised in a cast mainly to control pain.

The mean operating time was 35 minutes ( 25 to 45 ), with the exception of the patient with an additional fracture of the ulna $(90$ minutes). We did not feel that there was a significant learning curve because of our extensive experience of pinning fractures of the shaft. We now use $1.6 \mathrm{~mm}$

Table II. Grading of results after treatment of fractures of the neck of the radius

\begin{tabular}{|c|c|c|c|}
\hline Grade & Elbow movement & Radiological features & Symptoms \\
\hline Excellent & Normal range of movement & Anatomical position of head of the radius & None \\
\hline Fair & $\begin{array}{l}<10^{\circ} \text { restriction in one } \\
\text { plane or }<20^{\circ} \text { restriction in all planes }\end{array}$ & Minor irregularities & Intermittent and/or minimal pain \\
\hline Poor & $>20^{\circ}$ restriction in all planes & $\begin{array}{l}\text { Disproportion and deformity of the head } \\
\text { of the radius }\end{array}$ & Pemanent and/or severe pain \\
\hline
\end{tabular}



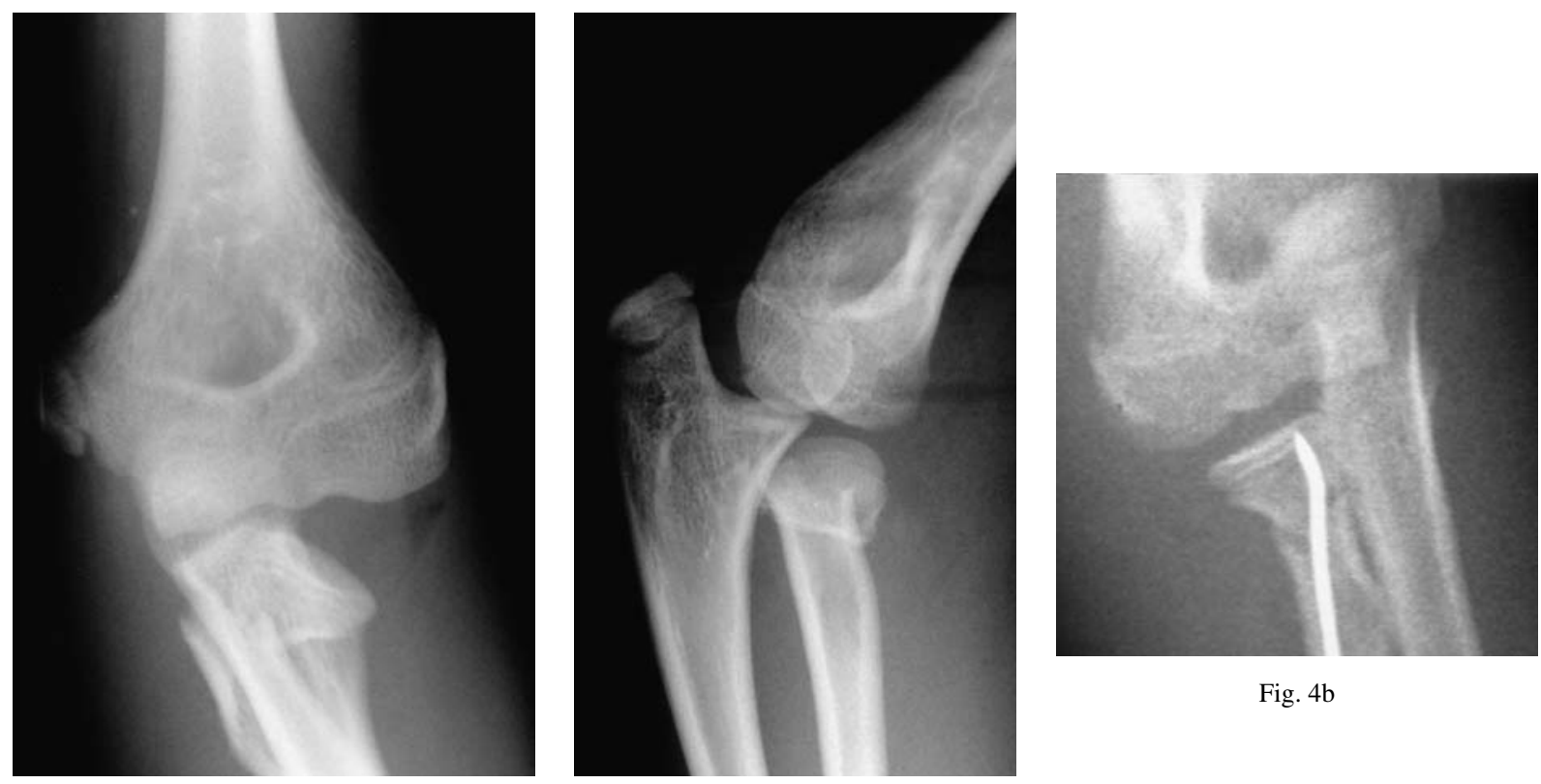

Fig. 4b

Fig. $4 \mathrm{a}$
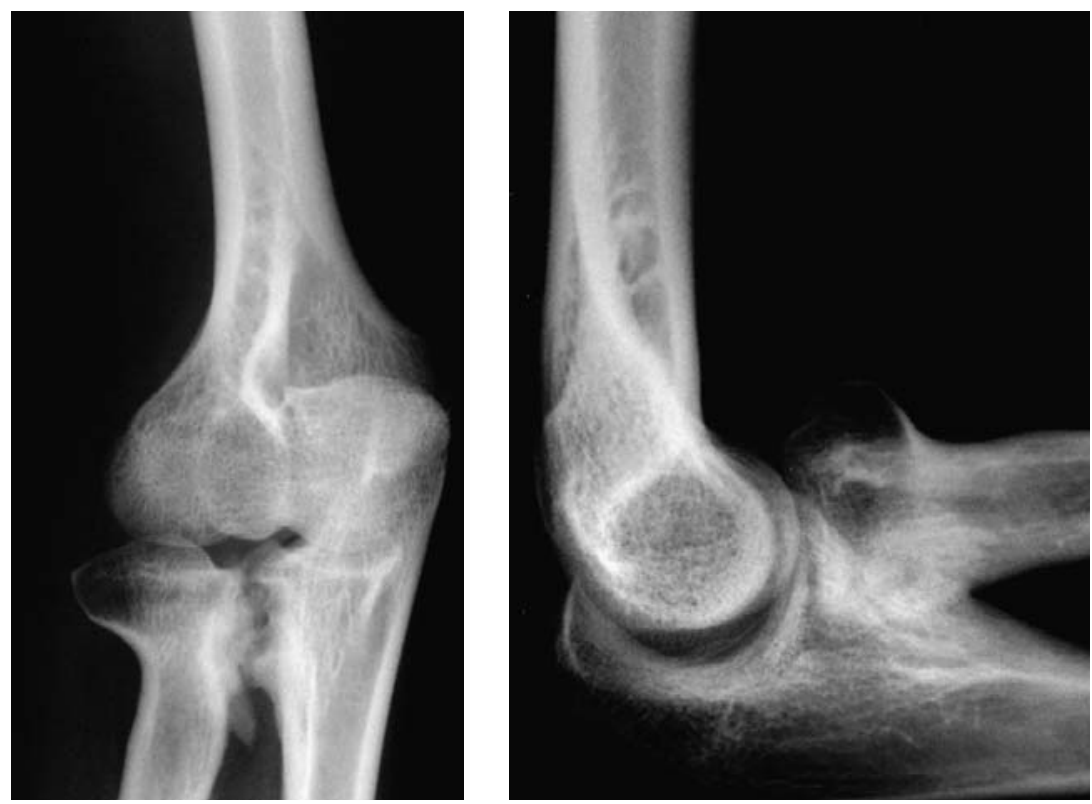

Radiographs showing anteroposterior (left) and lateral (right) views of the elbow of a 10-year-old girl. Figure 4a - Preoperative radiographs showing a grade-IV fracture with an angulation of $75^{\circ}$ and concomitant dislocation of the elbow. Figure $4 \mathrm{~b}$ - Intraoperative radiograph after closed reduction and intramedullary pinning with a K-wire. Figure $4 \mathrm{c}$ - Follow-up radiographs 18 months after the operation. Note the angulated, hypertrophic radial head and the radioulnar synostosis.

Fig. $4 \mathrm{c}$

$\mathrm{K}$-wires for all patients because they are much easier to insert. The mean radiation time was 3 minutes 30 seconds ( 2 minutes 47 to 4 minutes 10 ), except in the patient with an ulnar fracture in whom the radiation time was 10 minutes. The patient, the surgeon, and all operating theatre personnel wore prescribed protection garments and were exposed to $<0.01 \mu \mathrm{Gy} / \mathrm{s}$.

All patients were followed up clinically and radiologically at four weeks, at three months, and thereafter at sixmonthly intervals. Mobilisation of the elbow started after removal of the cast, i.e., four weeks after the operation. The
K-wire was removed when healing of the fracture had occurred clinically and radiologically.

\section{Results}

The results were graded as excellent, fair or poor as shown in Table II. Normal pronation/supination was defined as $85^{\circ} / 0^{\circ} / 90^{\circ}$, and normal flexion/extension as $160^{\circ} / 0^{\circ} / 0^{\circ}$ in boys and $160 \% \% 5^{\circ}$ in girls. Pronation/supination and flexion/extension were compared with those of the uninjured elbow. 
In all six patients, the postoperative course was uneventful. Radiological signs of consolidation were noted at four weeks and healing of the fracture was complete at three months after the injury. After removal of the pin at a mean of 4.25 months (6 weeks to 8 months) five of the six patients $(83.3 \%)$ showed complete clinical and radiological recovery with a normal range of movement of the elbow and forearm with the head in the anatomical position on the radiograph. The oldest patient in our series, who had also suffered dislocation of the elbow, showed unsatisfactory clinical and radiological recovery and was graded as poor. Severe impairment of pronation/supination $\left(25^{\circ} / 0^{\circ} / 10^{\circ}\right)$ and mild restriction of flexion/extension $\left(130^{\circ} / 0^{\circ} / 0^{\circ}\right)$ were present 2.5 years after injury. The radiograph showed a healed, but bulb-shaped head, angulated $20^{\circ}$ with a progressive radio-ulnar synostosis (Fig. 4).

\section{Discussion}

The management of fractures of the neck of the radius in children is controversial. ${ }^{3}$ In 1996 we published the results of the treatment of grade-IV fractures by open reduction and internal, transarticular fixation (ORIF). ${ }^{19}$ In that series, 10 out of 96 children with fractures of the neck had a grade-IV fracture. Eight were treated operatively, with one excellent $(12.5 \%)$ and six poor $(75 \%)$ results, while one patient $(12.5 \%)$ was lost to follow-up. Two were treated conservatively because of delayed referral, with a poor outcome in both. Our overall results compared very unfavourably with those published by other authors who reported excellent conclusions after ORIF in $50 \%,{ }^{11} 43 \%,{ }^{16} 38 \%,{ }^{20}$ $33 \%,{ }^{10}$ and $22 \%{ }^{1}$ of cases. Overall, however, the results from ORIF are not satisfactory. Only one in three patients has an excellent outcome, indicating that this may not be the most appropriate method to treat these difficult fractures.

We therefore changed to intramedullary pinning, originally described by Métaizeau et al. ${ }^{6,7}$ Our results using this method show that five of our six patients $(83 \%)$ achieved an excellent outcome. Métaizeau et $\mathrm{al}^{7}$ and GonzálezHerranz et $\mathrm{al}^{21}$ reported almost identical results with CIMP with an excellent outcome in grade-IV fractures in $82 \%$ and $83 \%$ of patients, respectively.

A number of other techniques have been advocated for the management of fractures of the neck of the radius. Percutaneous reduction using a K-wire or a Steinmann pin without subsequent fixation has been reported by several authors. ${ }^{2,9,14,15}$ None of these studies can be directly compared with our series or those of Métaizeau et $\mathrm{al}^{7}$ and González-Herranz et al, ${ }^{21}$ since the indications for reduction (angulation $>30^{\circ 15}$ and $>35^{\circ 9,14}$ ) and the grading systems used to assess outcome are different. In general, however, the results appear to be similar to those achieved by CIMP, and better than with ORIF. Futami et $\mathrm{al}^{5}$ and Biyani, Mehara and $\mathrm{Bhan}^{22}$ described percutaneous reduction with subsequent percutaneous pinning of the head. Futami et $\mathrm{al}^{5}$ reported excellent functional results in all ten patients, but four developed premature fusion of the epiphysis of the head. In the series of Biyani et $\mathrm{al}^{22}$ percutaneous reduction and pinning of grade-III and grade-IV fractures yielded excellent results in $43 \%$ of cases. We agree with both groups that grade-IV fractures require fixation after reduction to avoid redisplacement and repeated manoeuvres to achieve reduction which may compromise the blood supply to the neck. $^{7,16}$ We believe that CIMP is as easy and safe to perform as percutaneous pinning, but allows better positioning of the head of the radius.

An important prognostic feature is the presence of associated injuries. The only child in our study with a poor outcome had a concomitant dislocation of the elbow and was older than ten years. In most published studies, concomitant injuries were associated with unfavourable results. ${ }^{1,7,10,15,19,20,23}$ Some authors have suggested that outcomes in adolescent patients ${ }^{4,8,10,11,14,20}$ are associated with the limited capacity for remodelling due to the amount of growth remaining.

CIMP offers satisfactory stabilisation of the head of the radius while healing of the fracture occurs. The technique is safe, easy to perform and minimally invasive. It avoids additional surgical damage, and prevents redisplacement and repeated manipulations of the head. Early mobilisation of the joint with the wire in situ is possible and shortens the period of rehabilitation. Although our experience is based on a small number of patients, our results together with those of Métaizeau et $\mathrm{al}^{7}$ and González-Herranz et $\mathrm{al}^{21}$ suggest that CIMP is a good method of treatment of gradeIV fractures in children.

No benefits in any form have been received or will be received from a commercial party related directly or indirectly to the subject of this article.

\section{References}

1. Fowles JV, Kassab MT. Observations concerning radial neck fractures in children. J Pediatr Orthop 1986;6:51-7.

2. Pesudo JV, Aracil J, Barcelo M. Leverage method in displaced fractures of the radial neck in children. Clin Orthop 1982;169:215-8.

3. Radomisli TE, Rosen AL. Controversies regarding radial neck fractures in children. Clin Orthop 1998;353:30-9.

4. D'souza S, Vaishya R, Klenerman L. Management of radial neck fractures in children: a retrospective analysis of one hundred patients. J Pediatr Orthop 1993;13:232-8.

5. Futami T, Tsukamoto Y, Itoman M. Percutaneous reduction of displaced radial neck fractures. J Shoulder Elbow Surg 1995; 4:162-7.

6. Métaizeau JP, Prévot J, Schmitt M. Réduction et fixation des fractures et décollements épiphysaires de la tête radiale par broche centro-médullaire. Rev Chir Orthop 1980;66:47-9. (Eng. abstr.)

7. Métaizeau JP, Lascombes P, Lemelle JL, Finlayson D, Prevot J. Reduction and fixation of displaced radial neck fractures by closed intramedullary pinning. J Pediatr Orthop 1993;13:355-60.

8. Newman JH. Displaced radial neck fractures in children. Injury 1977;9:114-21.

9. Rodriguez Merchan EC. Percutaneous reduction of displaced radial neck fractures in children. J Trauma 1994;37:812-4.

10. Tibone JE, Stoltz M. Fractures of the radial head and neck in children. J Bone Joint Surg [Am] 1981;63-A:100-6.

11. Vocke AK, von Laer L. Displaced fractures of the radial neck in children: long-term results and prognosis of conservative treatment. $J$ Pediatr Orthop B 1998;7:217-22. 
12. Akatsu T. Percutaneous reduction in the treatment of radial neck fracture in children. Orthop 1957;8:269-71.

13. Feray C. Méthode originale de réduction "peu sanglante" des fractures graves de la tête radiale chez l'enfant. La Presse Medicale 1969;77:2155-6.

14. Bernstein SM, McKeever P, Bernstein L. Percutaneous reduction of displaced radial neck fractures in children. J Pediatr Orthop 1993; 13:85-8.

15. Steele JA, Graham HK. Angulated radial neck fractures in children: a prospective study of percutaneous reduction. J Bone Joint Surg [Br] 1992;74-B:760-4.

16. Steinberg EL, Golomb D, Salama R, Wientroub S. Radial head and neck fractures in children. J Pediatr Orthop 1988;8:35-40.

17. González-Buendia R, Esteban-Pérez SJ, Corbacho-Gironés JM, Rodriguez M. Las osteosintesis percutáneas: fines de Semana Traumatológicos 1975. Madrid: Publicaciones del Ministerio de Trabajo, Instituto Nacional de Previsión, 1976:213-47.
18. Judet J, Judet R, Lefranc J. Fracture du col radial chez l'enfant. Ann Chir 1962;16:1377-85.

19. Gutbrodt H. Langzeitverläufe nach kindlichen Radiusköpfchenfrakturen: Einfluss der Diagnostik und Therapie auf die Spätresultate. Inauguraldissertation, Universität Zürich 1996:1-47.

20. Vahvanen V, Gripenberg L. Fracture of the radial neck in children. Acta Orthop Scand 1978;49:32-8.

21. González-Herranz P, Alvarez-Romera A, Burgos J, Rapariz JM, Hevia E. Displaced radial neck fractures in children treated by closed intramedullary pinning (Métaiseau technique). J Pediatr Orthop 1997; 17:325-31.

22. Biyani A, Mehara A, Bhan S. Percutaneous pinning for radial neck fractures. Injury 1994;25:169-71.

23. Sessa S, Lascombes P, Prévot J, Gagneux E. Fractures of the radial head and associated elbow injuries in children. J Pediatr Orthop B 1996;5:200-9. 